\title{
Perfil de los comunicadores sociales desde la perspectiva de la comunicación humanizadora
}

\author{
Carlos Ayala Ramírez \\ Radio YSUCA \\ Universidad Centroamericana (UCA) \\ San Salvador
}

RESUMEN: En las actuales sociedades, los medios de comunicación gozan de un importante protagonismo. Suele decirse que la sociedad actual es una sociedad mediática, pero se olvida también que esta es una sociedad urgida de valores bumanizadores. En este artículo, el autor aboga por un perfil bumanizado de los comunicadores, frente a las concepciones mercadológicas imperantes.

ABSTRACT: The media have an important role in the contemporary societies. Some use to say that today's society is a mediatic society, but usually it is forgotten that this society needs humanizing values. In this esssay, the author pleads for a bumanized profile for journalists, as a response to the ruling marketing conceptions.

\section{Introducción}

Dignificar los medios de comunicación social pasa, entre otras cosas, por formar un nuevo modo de ser comunicadores y comunicadoras. A una práctica humanizadora de la comunicación le corresponde un 
determinado espíritu con el que ha de ser llevada esa práctica. La palabra espíritu no suele usarse dentro del los marcos conceptuales referidos a los medios de comunicación social. Aparte de que es una palabra que no ha gozado de buen cuño pues para algunos puede significar lo contrapuesto a la materia, algo que no tiene que ver con la realidad, algo que nos pone fuera de nuestras responsabilidades históricas. En contraposición a esta visión peyorativa de la palabra espíritu nos remitimos a tres intuiciones teóricas que no sólo dan luz sobre el tema, sino también constituyen bases argumentativas de nuestro planteamiento en torno a la necesidad de formar comunicadores con espíritu. Estas intuiciones son: el espíritu como talante vital (Pedro Casaldáliga), el espíritu de gentileza (Leonardo Boff) y la ecología del espíritu (Jon Sobrino).

El espíritu entendido como talante vital, como inspiración o voluntad profunda (Casaldáliga, 1992), es lo más hondo de una persona: sus motivaciones, sus ideales, su utopía, su mística por la que vive y lucha y con la cual contagia a los demás. Desde esa perspectiva se puede hablar de personas que tienen "buen espíritu" (veracidad, solidaridad, justeza, etc.), "mal espíritu" (falsedad, doblez, incoherencia, etc.), "mucho espíritu" (presencia y fuerza de motivaciones profundas) o, "sin espíritu" (sin ideales, sin pasión por la vida). Según esta visión el factor espíritu no es, en principio, un tema formalmente religioso, sino una realidad profundamente humana e ineludible.

El espíritu, entendido como espíritu de gentileza (Boff, 2004 a), es la razón cordial (la lógica del corazón) que tiene que ver con las personas y las relaciones sociales, que cuida de la subjetividad, del sentido de la vida y de la calidad de las relaciones humanas. A diferencia del espíritu de geometría (razón calculadora) que pone su énfasis en la clasificación y análisis de datos, el espíritu de finura o gentileza da centralidad a las personas, destinos y valores que están detrás de esos datos.

Esta forma de concreción del espíritu o de ser espiritual genera humanización en todos los ámbitos (incluido el de los medios de comunicación social). Crea una ecología del espíritu (Sobrino, 1996), cuyo dinamismo lleva a recuperar la utopía en contra del desencanto, a promover el espíritu de comunidad frente al individualismo aislacionista, a la apertura al otro versus el etnocentrismo cruel, a la creatividad versus el mimetismo, a la solidaridad versus el independentismo, a la verdad versus la propaganda y la mentira, a la memoria y el recuerdo versus el olvido, al compromiso con la justicia versus la pura beneficencia encubridora o tranquilizadora de la mala conciencia. 
Desde esta forma de entender el espíritu y la práctica que desencadena - y asumiendo el reto de humanizar los medios de comunicación socialproponemos un perfil de comunicador o comunicadora con espíritu, pero con espíritu utópico, crítico, de buen sentido, cuidador e intermediador. Veamos en qué consisten cada uno de estos rasgos.

\section{Comunicadores con espíritu utópico}

Vamos a clavar los ojos más allá de la infamia, para adizinar otro mundo posible: el aire estará limpio de todo veneno que no venga de los miedos humanos y de las humanas pasiones; en las calles, los automóviles serán aplastados por los perros; la gente no será manejada por el automóvil, ni será programada por la computadora, ni será comprada por el supermercado; ni será mirada por el televisor; el televisor dejará de ser el miembro más importante de la familia, y será tratado como la plancha o el lavarropas; la gente trabajará para vivir, en lugar de vivir para trabajar (...) los economistas no llamarán nivel de vida al nivel de consumo, ni llamarán calidad de vida a la cantidad de cosas (...) la muerte y el dinero perderán sus mágicos poderes, $y$ ni por defunción ni por fortuna se convertirá el canalla en virtuoso caballero (...) el mundo ya no estará en guerra contra los pobres, sino contra la pobreza, y la industria militar no tendrá más remedio que declararse en quiebra; la comida no será una mercancía, ni la comunicación un negocio, porque la comida y la comunicación son derechos humanos...

Adivinar otro mundo posible (E. Galeano, Patas arriba, la escuela del mundo al revés, Madrid, 1999).

En los últimos quince años, la dinámica de la historia ha sido adversa a las utopías. Los pragmatismos y utilitarismos han proclamado abiertamente el fin de estas. El futuro se ha visto más como una amenaza que como una posibilidad de construir realidades nuevas, humanizantes y humanizadoras. La utopía ha sido excluida de todos los campos: de la economía, de la política, de la educación, de la teología e incluso de los medios de comunicación social. Se ha pasado de desear lo ideal posible a gestionar o administrar lo real posible. En el mejor de los casos se desea el mal menor y, en el peor, se termina identificando lo vigente como la realidad última y definitiva. Sin embargo, aunque la utopía puede ser excluida o combatida, no puede ser anulada porque ésta responde a una 
dimensión de la realidad misma: su carácter abierto y dinámico a nuevas y mejores posibilidades. Pero, sobre todo, la realidad misma nos dice que no estamos en el mejor de los mundos posibles; al contrario, a la inveterada injusticia socio económica (profundizada por el neoliberalismo) se suman ahora nuevas formas de injusticias (étnicas, de género, culturales, ecológicas, comunicacionales, imperiales). En consecuencia, la búsqueda y construcción de un "mundo otro" debe ser un compromiso inmediato e inaplazable.

De ahí que la utopía es esencial como imagen movilizadora de las energías humanas, como horizonte que orienta y guía la praxis, como instancia crítica de la realidad, como alternativa al (des) orden establecido, como imagen visualizadora y anticipadora de un ideal (Tamayo, 2003). Pero ésta (la utopía) ha de ser construida con mucho y buen espíritu.

Ahora bien, ¿cómo los comunicadores podemos recuperar la utopía en el ámbito de los medios de comunicación social?

En primer lugar, si hay un uso deshumanizador de los medios que tiende a bloquear a la comunidad y menoscabar el bien integral de las personas alienándolas, manipulándolas o marginándolas; es imperativo volver al carácter esencialmente humano de la comunicación. Las definiciones técnicas de comunicación suelen olvidar esto que no por obvio deja de ser fundamental. Nos referimos al hecho de que el ser humano es un ser de relación y de comunicación, un ser, por lo tanto, dialógico. Esta naturaleza implica por lo menos tres cosas: Primero, que la persona y la comunidad humana son los sujetos de la comunicación y, en consecuencia, son el fin y la medida del uso de los medios de comunicación. Segundo, en coherencia con lo anterior, los comunicadores deben ejercer la comunicación como un servicio que responde a la necesidad de información veraz, de expresión propia, de acompañamiento, de sentido de pertenencia, de sentido de responsabilidad mutua que tienen la persona y la comunidad. Tercero, la meta de la comunicación social debe ser la humanización, esto es, el cultivo de aquellos valores que constituyen lo específicamente humano en su dimensión más positiva y realizante: respeto y valoración de la dignidad humana; capacidad de empatía y simpatía, de cuidado y comunión con y por el otro; preocupación por la calidad de la conciencia colectiva favoreciendo la racionalidad, la participación ciudadana informada, la verdad y el bien común. 
En segundo lugar, pensar el tema de la utopía en este ámbito -en un mundo que impone el pensamiento único neoliberal y donde la verdad de las mayorías pobres es oprimida y ocultada - exige poner a producir las tres opciones que la teología de la liberación (Sobrino, 2002) propone a los comunicadores y comunicadoras: opción por una comunicación liberadora, por una comunicación al servicio de los pobres y por una comunicación que favorezca la lucha por la justicia.

Debe ser liberadora porque en la realidad hay opresión y encubrimiento de la verdad. Hay políticos y empresas multinacionales que se sirven de la mentira como medio para el triunfo político y el éxito empresarial. Hay medios de comunicación de masas que no sólo no difunden información veraz, sino que se dedican a desinformar haciendo pasar como información lo que no es más que propaganda política.

El sistema masivo de medios suele desempeñar el papel de darle cierta "racionalidad" a las grandes mentiras del poder.imperial. La gran mentira neoliberal que presupone que la economía globalizada (del libre comercio mundial) resulta la más apropiada para elevar mundialmente la riqueza, erradicar la pobreza y disminuir las profundas desigualdades sociales. No obstante, los datos que año con año presenta el Programa de las Naciones Unidas para el Desarrollo, revelan que las brechas aumentan en vez de disminuir. El engaño de la cultura occidental que impone como horizonte de la humanidad el éxito individual, el lucro sin freno y el consumo sin límites. Pero, en realidad, por ese camino sólo llegamos al empobrecimiento del ser humano, a la depredación de recursos y a la insolidaridad con los más pobres y con las generaciones futuras. El engaño de las guerras "preventivas", que bajo el pretexto de combatir el terrorismo o llevar la democracia occidental como tabla de salvación de los pueblos oprimidos, produce más bien muerte masiva de seres humanos, destrucción de recursos y aniquilación de culturas.

Si la verdad está esclavizada bajo los intereses de la riqueza y el poder, que duda cabe de la legitimidad, necesidad y urgencia de una comunicación liberadora. Comunicación que no sólo busca liberarse de las grandes mentiras, sino comunicar verdad sobre la cual han de construirse nuevas estructuras fomentadoras de la dignidad humana y de la honradez con la realidad.

Debe estar al servicio de los pobres, es decir, que dé voz e imagen a aquellos que, siendo mayorías, no se les permite mostrar su realidad, 
aunque la sufren y padecen. Pobres son, desde una perspectiva cualitativa (Sobrino, 1999), aquellos y aquellas cuya máxima tarea y su mayor dificultad consisten en sobrevivir; el silenciado, que no tiene dignidad ni palabra que decir; el impotente, que no tiene poder para hacer valer sus derechos; el despreciado, porque no alcanza a cumplir con los requisitos de la cultura predominante; el in-significante, con el que no se cuenta; el in-existente, que es considerado sobrante por el aparato productivo; los excluidos, a causa de su raza, cultura o género. La comunicación liberadora que opta por el pobre hace de su realidad (la de los pobres) una realidad central y comunicada. Por eso rompe con el anonimato al que han sido sometidas las mayorías por los grandes medios de comunicación (les pone rostro, nombre, historia); mira al mundo desde esas mayorías pobres, porque desde ese lugar se ve más y mejor la realidad, tanto en lo que es de suyo (una realidad injusta e inhumana), como en lo que tiene que hacerse con ella (transformarla hacia una civilización que asegure una vida digna para todos); abre una comunicación horizontal con ellos (sabe escucharlos), como condición de posibilidad para que, pobres y comunicadores, tomen conciencia de lo injusto de esa situación y de sus responsabilidades en los cambios sociales.

La comunicación liberadora debe favorecer los consensos sociales en torno a la viabilidad del "otro mundo posible" impulsado por el movimiento social mundial. Es decir, debe poner su propio peso al servicio de la solidaridad, de la mundialización de los derechos humanos, de la socialización de la democracia como valor universal (una democracia global que respete el pluralismo social y cultural), del control social de los capitales especulativos, de la cultura del cuidado (que previene los daños futuros y regenera los daños pasados), de la civilización del trabajo (que busca sustituir la acumulación privada del mayor capital posible, por la dignificación del trabajo personal o colectivo para asegurar la satisfacción de las necesidades básicas y la autorrealización humana).

En tercer lugar, otro ámbito de acción de los comunicadores con espíritu utópico (que buscan nuevas y mejores posibilidades comunicativas), lo constituye la lucha por la democratización de los medios.

Resulta paradójico que en la llamada era de la comunicación global no todos tienen un puesto en el uso de los medios. Algunos consideran que los nuevos medios tecnológicos —en virtud de su relativa facilidad de acceso y costos no necesariamente onerosos- ofrecen una gran 
posibilidad para que la realidad de los pobres se haga presente en el imaginario colectivo. Sin embargo, aunque la Internet ha crecido aceleradamente en buena parte del mundo - de 16 millones de usuarios en 1995 a más de 400 millones en el año 2000, y se espera que llegue a 1000 millones de usuarios en el 2005-, en América Latina, por ejemplo, sólo el 12 por ciento de las personas estará conectado para el año 2005. En este terreno, al igual que en el económico y social, la globalización resulta también ser excluyente e inequitativa.

La utopía en este plano conlleva una exigencia derivada de los derechos humanos: todos y todas deben ocupar un puesto en la comunidad de comunicación; todos han de tener cabida en ella y han de poder hablar y ser escuchados. Para que esto suceda hay que poner en vigencia el derecho ciudadano de expresar sus ideas, opiniones y críticas a través de los medios masivos.

Hay que democratizar los medios para que éstos no se usen de forma exclusiva en beneficio de un sector, de una ideología y de unos intereses hegemónicos; para que el ciudadano común no quede al margen del proceso de la comunicación social, como mero destinatario o consumidor pasivo de mensajes. Una sociedad con reales pretensiones democráticas debe posibilitar el acceso de los ciudadanos a los medios y la pluralidad de los flujos informativos. En la concreción de este ideal consustancial a la democracia, deben tomar parte activa los comunicadores y comunicadoras.

\section{Comunicadores con espíritu crítico}

En una ocasión se quejaba un discípulo a su maestro: "Siempre nos cuentas historias, pero nunca nos revelas su significado". El maestro le replica: " $i T e$ gustaria que alguien te ofreciera fruta $y$ la masticara antes de dártela?”

Nadie puede descubrir tu propio significado en tu lugar. Ni siquiera el Maestro.

Come tu mismo la fruta (A. de Mello, El canto del pájaro, Sal Terrae, Santander, 1982).

El ciudadano común otorga, en principio, un cierto grado de confianza a los medios de comunicación social. Los ciudadanos asumen como verdaderos los contenidos informativos de los medios; su juicio crítico concede, a lo sumo, que tales contenidos presentan verdades posibles e 
incompletas, pero no posibles mentiras. Si así fuera, nadie se expondría a ellos. Asumen, además, que no hay en tales contenidos voluntad alguna por distorsionar la percepción de la realidad por parte de los informadores. Y que, del conocimiento de dichos contenidos, depende en gran medida su capacidad para poder actuar racional e informadamente en la sociedad. La confianza en los medios deriva del carácter institucional de éstos, es decir, de sus patrones de acción y valores definidos, previsibles en unos modos de desempeño que se han ido consolidando con el paso del tiempo (Álvarez,2002).

No obstante, cuando los contenidos informativos son sometidos al análisis y la verificación con la realidad, esa confianza se desmorona al constatar que en una gran cantidad de la información recibida, encontramos una visión parcial y/o superficial de la realidad, una acumulación de hechos sin contexto, un predominio de la actualidad y la omisión de hechos esenciales llevados a la "irrealidad" porque no han sido considerados "noticiables".

Con la aparición de Internet y las nuevas tecnologías de la información, parecieron abrirse novedosas posibilidades para acceder a la información y para desarrollar una comunicación interactiva. Los más entusiastas se atrevieron a afirmar que por esta razón el tiempo del monopolio de la producción y difusión de mensajes había llegado a su fin.

Sin embargo, este panorama tiene sus puntos de inflexión. Un ejemplo claro de lo que afirmamos lo representa el manejo manipulado y controlado de la información sobre el atentado del 11 de septiembre de 2001 y las consecuentes acciones que se derivaron del mismo (invasión a Afganistán e Irak). Los más influyentes medios de comunicación en Estados Unidos, tanto electrónicos como impresos, se convirtieron en medios oficiosos de las posiciones y de las medidas del gobierno del presidente Bush; favoreciendo y justificando las guerras de invasión. Los periodistas que se atrevieron a cuestionar las decisiones de Bush fueron considerados antipatriotas. La información alternativa que se ofrecía en la red era minimizada o marginada por los grandes medios. Se satanizaron las visiones críticas y se impuso la versión oficial de los hechos. De tal modo que, hoy día, en la conciencia colectiva hay un claro registro del 11 de septiembre de 2001, pero total ausencia de información sobre el 7 de octubre de 2001 (fecha del inicio de los bombardeos contra Afganistán), y menos del 30 de marzo de 2003 (inicio de la guerra de invasión contra Irak). Los medios de comunicación ejercen un papel preponderante en la 
formación de nuestra conciencia política. Nos hacen ver la realidad que ellos han considerado la más "noticiosa" y ella incide en la construcción que nos hacemos del mundo.

Ahora bien, en un marco mediático que tiende hacia el encubrimiento de la realidad mediante la manipulación de los acontecimientos - ocultando deliberadamente hechos que desfavorecen a los intereses que representan y enalteciendo aquellos que les benefician-, el cultivo de la fugacidad y el olvido, la acumulación de información sin contexto, el uso manipulado del lenguaje y la progresiva sustitución de la cultura por el mero entretenimiento; se torna en un imperativo ético que los comunicadores - también los interlocutores, pero en esta ocasión nos centramos en los primeros - vuelvan al espíritu de los maestros de la sospecha (Descartes, Kant, Marx, Feuerbach). Esto es, volver a ponderar la crítica como actitud y como posición gnoseológica.

Ello implica cuando menos tres aspectos: primero, problematizar, es decir, profundizar con el auxilio de las ciencias sociales aquellos planteamientos que se hacen pasar como evidentes en el imaginario colectivo ("El capitalismo es el mejor de los sistemas"; "El comunismo es un sistema fracasado"; "Los tratados de libre comercio contribuirán a combatir la pobreza"; "El libre mercado regula equitativamente los costos y los beneficios entre productores y consumidores", etc.); segundo, dudar, esto es, someter al discernimiento y a la verificación histórica aquellas afirmaciones que se dan por ciertas en torno a diversos tópicos ("Vivimos en democracia"; "Existe una absoluta libertad de expresión"; "La realidad actual ha cambiado con respecto a los problemas del pasado", etc.); tercero, desenmascarar - sacar a la superficie las conexiones ocultas- los intereses particulares que se hacen pasar como bien común, las opiniones partidistas que se hacen pasar como públicas, la generalización de lo particular (exagerar las bondades de un sistema sólo por sus resultados macroeconómicos) y la deformación del peso específico de la información (minimizar los datos de la realidad que ponen en cuestión la justeza del sistema).

La necesidad de revertir el encubrimiento y la manipulación, exige de los comunicadores éticos un esfuerzo de racionalidad por situar cada acontecimiento en su contexto social e histórico. Exige también la actitud de autocrítica para mantener la honradez con lo real, frente a aquellas presiones que la limitan o la pervierten: los intereses de partido, las prebendas, las amenazas, la propia ideología, el conflicto de intereses, etc. 
Supone, por otra parte, la posibilidad de contar con medios de comunicación que se conciban como instrumentos para comunicar a los ciudadanos la información que necesitan para ser pueblos más libres (de todo cuanto frena su desarrollo humano), y más comprometidos con la refundación de la sociedad (avance hacia una democracia real)

\section{Comunicadores con buen sentido y sana razón}

Estaba un día Diógenes plantado en la esquina de una calle y riendo como un loco.

“¿De qué te ries?”, le preguntó un transeúnte.

"¿Ves esa piedra que bay en medio de la calle? Desde que llegué aqui esta mañana, diez personas ban tropezado en ella y ban maldecido, pero ninguna de ellas se ha tomado la molestia de retirarla para que no tropezaran los otros".

La piedra en medio de la calle (A. de Mello. La oración de la rana t.1, Sal Terrae, Santander 1989, p.226).

La ética comunicativa propone definir la responsabilidad moral de las empresas informativas de acuerdo a su poder o capacidad para influir en dos aspectos básicos: en la formación de la voluntad individual (los medios como formadores de las personas) y en la formación de la voluntad colectiva (los medios como formadores de una opinión pública de calidad). La responsabilidad moral exige, desde esta doble aproximación, que los medios cultiven los valores humanistas, garanticen la información no sólo como un derecho básico, sino como un bien social, desarrollen su función educativa, se abran a la participación ciudadana y asuman el compromiso de la salvaguarda de los derechos humanos (García, 2003).

Sin embargo, el funcionamiento actual de la mayoría de medios de comunicación se orienta en un sentido contrario: su fuerza socializadora responde a criterios económicos y empresariales; favorecen el consumismo, la violencia y la manipulación de necesidades; ofrecen una pobre y uniforme visión de la realidad; la concentración empresarial y la incidencia de la publicidad convierten a los medios en un instrumento de intereses económicos, ajenos a toda función educativa y de formación de una opinión crítica.

La recuperación de la función educativa y de una opinión pública crítica implica, entre otras cosas, desarrollar en los comunicadores el buen sentido y la sana razón. Esto ayudará a que los comunicadores -y los 
medios para los que trabajan - no centren su atención informativa únicamente en la actualidad más evidente e inmediata, sin prestar interés a sus causas políticas, históricas, económicas, etc. Ayudará a comprender que lo que se presenta como información no es sólo una parte de la realidad, sino que muchas veces es también la parte menos importante, la menos explicativa (sin atención a lo humano, a las causas, a los antecedentes).

El buen sentido y la sana razón consisten en saber distinguir lo esencial de lo secundario, lo real de lo aparente, lo relativo de lo absoluto, la parte del todo, lo particular de lo general, lo coyuntural de lo estructural, lo importante de lo urgente, la información de la propaganda. En una palabra, consiste en la capacidad de ver y poner las cosas en su debido lugar. Cuando esto ocurre, se tiene la palabra certera, el comportamiento requerido y se acierta con el núcleo de las cosas ante cada situación concreta. El buen sentido y la sana razón nos llevan a la recta comprensión de la cosas (capacidad de discernir entre lo trivial y lo accesorio), al recto modo de pensar (con independencia, con autocrítica, sin ideologizaciones), al recto modo de comunicar (buscando la verdad, la justeza con la realidad, la palabras atinadas).

El buen sentido y la sana razón constituyen un efectivo antídoto contra las verdades parciales que ocultan deliberadamente aspectos de la verdad completa (se informa de los éxitos macroeconómicos del sistema neoliberal, pero no se informa del impacto contraproducente, humano y medio ambiental, que han supuesto tales "éxitos"); contra el sensacionalismo, que prefiere el espectáculo (lo extravagante, el morbo, la curiosidad malsana) al conocimiento racional de la realidad; contra la manipulación del pasado, que presenta como "glorias", hechos que a lo mejor no son más que injusticias y crueldad; contra el fomento del olvido, que niega la posibilidad de conocer y cultivar la memoria y la identidad históricas; contra la aparente asepsia de algunos comunicadores, que bajo un ropaje de imparcialidad, divulgan informaciones claramente sesgadas; contra el tipo de publicidad nociva, que hace promesas falsas en los productos que se anuncian, fomenta un consumismo alienante, explota los instintos sexuales, crea falsas necesidades y banaliza los aspectos fundamentales de la vida humana (el amor, la felicidad, la familia, el sentido de la vida).

El buen sentido y la sana razón posibilitan que los comunicadores mantengan: la independencia y la no manipulación de las noticias como

\section{5}

Perfil de los comunicadores sociales desde la perspectiva de la comunicación humanizadora 
salvaguarda del derecho ciudadano a estar bien informados; la disposición a reconocer y a enmendar los propios errores; el reconocimiento de que el público tiene derecho a conocer la fuente en la que se apoya determinada información; el reconocimiento de que el derecho a la información es primariamente del público, no del periodista; la actitud de no apoyarse ni divulgar rumores, a sabiendas que ellos no son noticia; la actitud de verificar cualquier acusación, cuando esté de por medio el honor de alguien, antes de hacerse pública; el esfuerzo por distinguir lo que es información de lo que es su opinión.

\section{Comunicadores con espíritu cuidador}

Preguntó un guru a sus discípulos si sabrían decir cuándo acababa la noche y empezaba el día.

Uno de ellos dijo: "Cuando ves a un animal a distancia $y$ puedes distinguir si es una vaca o un caballo".

"No", dijo el guru

"Cuando miras un árbol a distancia y puedes distinguir si es un mango o un anacardo"

"Tampoco", dijo el guru.

"Está bien", dijeron los discípulos, "dinos cuándo es".

"Cuando miras a un hombre al rostro y reconoces en él a tu bermano; cuando miras a la cara a una mujer y reconoces en ella a tu bermana. Si no eres capaz de esto, entonces, sea la hora que sea, aun es de noche".

Cómo distinguir la noche del día (A. de Mello, La oración de la rana t.1, Sal Terrae, Santander 1989).

Leonardo Boff (Boff, 2004 b), afirma que Occidente siempre ha tenido una dificultad para acoger al otro. Su estrategia predominante ha sido negarlo, ya sea mediante la incorporación, el sometimiento o la pura y simple destrucción. El carácter imperial de Occidente se funda en su presunción de ser el mejor en todo. Pero en Occidente - agrega Boff- encontramos otra vertiente que lo cura de esa arrogancia: la tradición judeocristiana. En esta tradición el otro es todo porque a través de él se da el amor y en él se esconde Dios, que también se hizo otro. En dicha tradición se dice: "Haz justicia al huérfano, a la viuda, al extranjero". Aquí encontramos una forma concreta de responsabilidad por el otro, de alteridad cuidadora. 
El cuidado como actitud humana fundamental (Boff, 2002), como modo de ser, significa desvelo, solicitud, diligencia, gentiliza, atención, delicadeza. El cuidado refuerza la vida, atiende las condiciones ecológicas, sociales y espirituales que permiten la reproducción de la vida con dignidad. En ese sentido asume una doble función: de prevención de daños futuros y de regeneración de daños pasados. Es una relación amorosa para con la realidad cuyo objetivo es garantizar su subsistencia y abrir el espacio necesario para su desarrollo. Los humanos debemos poner cuidado en todo: cuidado por la vida, por el cuerpo, por el espíritu, por la naturaleza, por la salud, por la persona amada, por el que sufre y por la casa común. Sin cuidado la vida perece.

La nota dominante en el mundo actual es el descuido, la indiferencia y el abandono. En una palabra, la falta de cuidado. Hay un descuido y una indiferencia por la vida de los niños y los jóvenes (en América Latina, África y Asia, existen millones de niños y jóvenes a los que se les niega la infancia, la inocencia y la posibilidad de soñar con una vida digna). Hay un descuido y una indiferencia por el destino de los pobres y marginados de la humanidad (según datos de la FAO, mueren cada hora en el mundo mil personas por hambre). Hay un descuido de la identidad social y cultural (millones de seres humanos se sienten desarraigados de sus propios valores). Hay un descuido de la dimensión espiritual del ser humano (no se cultiva el espíritu de honradez, de misericordia, de ternura, de respeto mutuo). Hay un descuido de los asuntos públicos (predomina una política sin ética). Hay un descuido de la sexualidad humana (predomina una práctica sexual entendida como diversión sin freno). Hay un descuido de nuestro entorno natural (predomina una depredación y consumo sin límites).

La sociedad contemporánea, llamada sociedad de la información y del conocimiento, está creando, contradictoriamente, cada vez más incomunicación y soledad entre las personas. La Internet puede conectarnos con millones de personas sin que tengamos que encontrarnos con nadie. Se puede comprar, vender, realizar pagos, trabajar, pedir comida, ver películas sin hablar con nadie. Para viajar, conocer países, visitar bibliotecas o pinacotecas no necesitamos salir de casa. Todo no viene a casa vía on line. El mundo virtual ha creado un nuevo hábitat para el ser humano, caracterizado por el encapsulamiento en uno mismo. Frente a esta pérdida de contacto humano (de empatía), el cuidado puesto en práctica en el ámbito de la comunicación social, nos plantea la necesidad 
de la relación cuidadosa con la persona concreta (sus necesidades, angustias, esperanzas, alegrías) y con la realidad concreta (sus resistencias, contradicciones y posibilidades). Nos plantea la necesidad de recuperar y hacer central a los sujetos de la comunicación, es decir, a las personas. De dar un salto cualitativo y colocar "al otro" como luz de la comunicación. El cuidado también demanda la necesidad de superar la tendencia generalizada a identificar comunicación sólo con aquello que proviene de los medios de comunicación social (que suelen reducir la comunicación a la información), olvidando que la comunicación en esencia es comunicación interpersonal, comunicación entre personas.

La recuperación de los sujetos de la comunicación pasa por revertir la condición a la que los medios de masas han convertido a las personas. Para los mass media éstas son clientes, consumidores, usuarios, masa, audiencia, receptores. Los comunicadores con talante cuidador están llamados a dignificar no sólo los procesos de la comunicación, sino ante todo a sus interlocutores, concibiéndolos como verdaderos sujetos de la comunicación.

Algunas propuestas, en este sentido (Catela, 2002), enfatizan: la puesta en práctica de una ética de la recepción que valora al interlocutor no como simple receptor, cliente o usuario, sino como persona concreta (sujeto de derechos, de responsabilidades, de necesidades, de posibilidades); la opción por cerrar las brechas digitales incluyendo a lo que hoy día se conoce como los pobres informativos (democratización de la comunicaciones); el tránsito de ser usuarios anónimos a interlocutores cualificados (con capacidad de discernimiento crítico); la formación de los interlocutores de cara a que analicen con rigor el contexto en el que se mueven para decidir con conocimiento de causa qué elige y qué descarta, convencido del valor que tiene su aporte personal en la configuración del fenómeno comunicativo (si no hay consideración y formación del interlocutor no hay una verdadera comunicación, no hay fomento de la participación democrática y las mayorías carecerán de opinión formada); el distanciamiento crítico respecto a los contenidos informativos, en tanto éstos no agotan ni el conocimiento de la realidad ni la complejidad de la misma (hay otras mediaciones de acceso a la realidad: la familia, la educación, la religión, el arte, las investigaciones, el contacto directo, la comunidad, etc.).

En suma, el cuidado, en tanto capacidad de empatía, simpatía y gentileza hacia los otros, puede promover —entre los comunicadores y 
entre éstos y sus interlocutores- el espíritu de comunidad, frente al egoísmo e individualismo campantes; la solidaridad con el débil, frente a la indiferencia por el sufrimiento infligido injustamente; la lucha por la justicia, frente a la pura beneficencia con la que se encubre y pretende paliar la inequidad; la búsqueda de la verdad, frente a la propaganda y la mentira encubridoras de la realidad; el desarrollo de la memoria histórica, frente al olvido que degenera en impunidad e ingratitud hacia las víctimas; el cultivo de la creatividad, frente al mimetismo que fácilmente degenera en pérdida de identidad; el compromiso con la protección de nuestra casa común, frente al consumo y depredación irresponsables.

\section{Comunicadores con espíritu intermediador}

En cierta ocasión, Buda se vio amenazado de muerte por un bandido llamado Angulimal.

"Sé bueno", le dijo Buda, "y ayúdame a cumplir mi último deseo. Corta una rama de ese árbol".

Con un golpe de su espada, el bandido bizo lo que le pedía Buda. "¿Y abora qué?", le preguntó a continuación.

"Ponla de nuevo en su sitio", dijo Buda.

El bandido soltó una carcajada: "iDebes estar loco si piensas que alguien puede hacer semejante cosa!".

"Al contrario", le dijo Buda. "Eres tú el loco al pensar que eres poderoso porque puedes herir y destruir. Eso es cosa de niños. El poderoso es el que sabe crear y curar".

Buda y el bandido (A, de Mello, La oración de la rana, t.2, Sal Terrae, Santander 1989).

$\mathrm{El}$ poder de intermediación —entre la realidad y la sociedad- de los medios de comunicación social se expresa, al menos, de dos modos: como intermediarios de las instancias del poder predominante (político, económico o simbólico) o como intermediarios del poder - real o potencial - que tiene la ciudadanía.

El poder fáctico de los grandes medios de comunicación social habitualmente se expresa en su capacidad de generar agenda, de predisponer a la opinión pública a favor o en contra de diferentes iniciativas y de erosionar la imagen de figuras consideradas enemigas o adversarias. Estos medios suelen utilizar este poder en beneficio de los intereses

Perfil de los comunicadores sociales desde la perspectiva de la comunicación humanizadora 
políticos, económicos e ideológicos que representan, o a los que son afines (especialmente los vinculados al gran capital). De tal modo que este vínculo ha fortalecido a ambos: los grandes medios se presentan como suprapoderosos (fiscalizan a mundo y medio sin que nadie pueda fiscalizarlos a ellos), y el gran capital es un factor de poder mucho más real, porque se ha venido apoderando de los instrumentos mediáticos haciendo prevalecer su visión y sus intereses. Así, los medios de comunicación se constituyen en un intermediario, en un eco social y constructor de discursos (hegemónicos), en un informador fragmentario y en un moldeador de la opinión pública.

Sin embargo, también existen medios de comunicación que han logrado cierta independencia con respecto a las estructuras partidarias e ideológicas de los grupos hegemónicos. El poder de estos medios proviene (Pérez, 2000) - no tanto de su amplia cobertura, de sus extraordinarias posibilidades técnicas, de sus recursos financieros, de sus vínculos con el poder político y económico — sino de su capacidad de intermediación ciudadana. Su poder aumenta en proporción a su capacidad de escuchar el "eco" — ser intermediarios - y de lograr un "eco" — resonancia — de los otros espacios y agentes de comunicación de la sociedad civil (las cooperativas, las familias, las organizaciones comunales, los grupos excluidos, las comunidades eclesiales de base, las iglesias, las religiones, los ciudadanos comunes).

El medio y el comunicador de intermediación ciudadana, posibilitan que el reclamo de la ciudadanía llegue a donde debe llegar. Hace oír la voz de la gente ante las instancias correspondientes. Y si la gente no puede hablar directamente con las autoridades, ofrece el peso de su propia voz para que éstas (las autoridades) escuchen, para hacer valer la denuncia y encontrar una solución justa a las demandas de la ciudadanía. El ejercicio de la ciudadanía plena es poder y la intermediación es ejercicio de ese poder (Radialistas, 2005).

Este modo de intermediación abre paso a la denuncia relacionada con la arbitrariedad, la violación a derechos humanos, la impunidad, etc. (fundamentada en los datos y en el análisis de sus causas), a la interpelación (búsqueda de responsables, búsqueda de soluciones), al seguimiento de procesos (verificación de las promesas y compromisos). Está orientado a incidir en la construcción de una ciudadanía plena medida por el ejercicio real de los derechos cívicos, sociales, culturales y económicos de la población. Medida también por la existencia de personas críticas, creativas 
y cuidadoras. Es decir, personas que tienen criterios y buenas razones para, por un lado, desenmascarar las formas de encubrimiento de la realidad, y por otra parte, para fundamentar sus propios planteamientos y proyectos. Personas creativas que identifican potencialidades de la realidad y proponen alternativas - a los problemas o desafíos de la sociedaddeseables y posibles. Personas cuidadoras que prestan atención a las condiciones y sentido de la vida, que distinguen lo que es urgente de lo que no lo es, que establecen prioridades y aceptan procesos, que ponen el bien común por encima del bien particular, que son responsables de la calidad de vida social y ecológica, y que da valor a la dimensión espiritual (persona ética).

El desarrollo democrático de una sociedad se mira fortalecido a través de la intermediación ciudadana de los comunicadores y medios independientes, en la medida en que éstos cultivan la participación ciudadana informada, obligan a los gobernantes a rendir cuentas, fomentan la conciencia crítica de sus interlocutores, abren espacios para el debate, mantienen un distanciamiento crítico con el poder y contribuyen a la solución de conflictos mediante el diálogo, la negociación y el consenso.

Recuperar el poder de los medios en función del bien común, de la sociedad considerada como un todo, de la humanización de la cultura, la política y la economía; son los retos de este tipo de intermediación. El poder mediático con capacidad de crear y sanar es aquel que opta por la opinión pública mundial que quiere que se conserve la paz, que se opone a la tortura y al trato inhumano, al privilegio o la dominación, y que quiere que se actúe contra la pobreza, el hambre y la exclusión en la que se encuentran las mayorías. Es el poder que puede contribuir a mejorar la calidad de vida de cada uno y de todos.

REFERENCIAS BIBLIOGRÁFICAS

Álvarez, C. (2002). "La manipulación informativa". En Agejas J. y Serrano, F. (coords.), Ética de la comunicación y de la información, Ariel, España, pp. 95-110.

Boff, L. (2002). El cuidado esencial. Trotta, Madrid. 
.(2004a)."Espíritu de gentileza" bttp://werere.servicioskoinonia.org/ boff/articulo.phpnum062 -.(2004 b). "El otro lo es todo".

http: //www.servicioskoinonia.org/boff/ articulo.php.num092

Casaldáliga, P. y Vigil, J.M. (1992). Espiritualidad de la liberación. UCA Editores, San Salvador.

Catela, I. (2002). "Ética de la recepción". En Agejas J. y Serrano, F. (coords.), op. cit. pp. 111-113.

García, D. (2003). "Confianza y poder: la responsabilidad moral de las empresas de comunicación". En Cortina, A. (comp.), Construir confianza, Editorial Trotta, Madrid, pp. 195-220.

Pérez, M. (2000). "La comunicación: El poder de la gente". En Vega Jiménez, P. (comp.), Comunicación, política e identidad, Editorial de la Universidad de Costa Rica, San José.

Radialistas (2005). "El periodismo de intermediación". www.radialistas.net. Sobrino, J. (1996). "Reflexiones sobre la evangelización en la actualidad". En Revista Latinoamericana de Teología, No. 39, pp. 297-299.

- (1999). "Los mártires latinoamericanos. Interpelación y gracia para la Iglesia”. En Revista Latinoamericana de Teología, No. 48, pp. 307-330.

- (2002). "Liberación de la verdad oprimida". En Ayala, C. (comp.), Comunicación e inspiración cristiana, UCA Editores, San Salvador, pp. 126-138.

Tamayo, J. (2003). "Rehabilitación crítica de la utopía en tiempos oscuros". http://www.servicioskoinonia.org/relat/338.htm 